\title{
The Effect of Surface Finish on Sculptured Shape Utilizing Scanned Data - Reversed Engineering (CATIA V5 \& DELCAM)
}

\author{
Sundi Syahrul Azwan ${ }^{1, *}$, Jumali Muhammad Syafik ${ }^{1}$, Attan Hassan $^{1}$ and R.Abdullah R. \\ Izamshah $^{2}$ \\ ${ }^{1}$ Faculty of Engineering Technology, Universiti Teknikal Malaysia Melaka, Hang Tuah Jaya, 76100 \\ Durian Tunggal, Melaka, Malaysia \\ ${ }^{2}$ Faculty of Manufacturing Engineering, Universiti Teknikal Malaysia Melaka, Hang Tuah Jaya, \\ 76100 Durian Tunggal, Melaka, Malaysia
}

\begin{abstract}
The ultimate aim of this study was to investigate the effect of surface finish for a machined part which was programmed by two popular CAD/CAM software namely Catia V5 and Delcam using scanned data obtained from one of the Reverse Engineering methods namely ThreeDimensional (3D) scanning process. A gaming mouse was chosen as the physical part to be scanned and machined because of its sculptured shape and wavy looks. In this study, simultaneous three-axis machining programs were created and machined using three-axis Computer Numerical Control (CNC) Milling machine. Initially, the physical gaming mouse gone through the first process called scanning process using a 3D scanner; model $700 \mathrm{CX}$ in order to capture the 3D CAD data in points cloud form. The raw scanning data then gone through editing process to obtain better surfaces. Moreover, the stable and edited CAD model then undergone $\mathrm{CAD} / \mathrm{CAM}$ programming process for both mentioned software respectively. There were ten random points chosen to be analyzed for the surface roughness analysis. The arithmetic mean value ( $\mathrm{Ra}$ ) was used as the roughness value reference. The results reveal that the average surface roughness for the ten points was $0.232 \mu \mathrm{m}$ for Catia V5 whilst for Delcam was around $0.274 \mu \mathrm{m}$. Ultimately, Catia V5 producing better surface finish compared to Delcam software concluded from the analysis carried out as presented in this paper.
\end{abstract}

\section{Introduction}

$\mathrm{CAD} / \mathrm{CAM}$ system is commonly used in daily engineering tasks. CAM may be defined as the use of computer systems to plan, manage, and control the operations of a manufacturing plant through either direct or indirect computer interface with the production resources of the plant. The geometric model generated during the CAD process forms the basis for the CAM process. Various activities in CAM may require different types of information of the

\footnotetext{
* Corresponding author: syahrul.azwan@utem.edu.my
} 
CAD process [5]. As it is developed through time and widely used, it needs the best decision to choose the best software to be owned. In the process of product design and manufacture, this role is becoming increasingly important as competitive pressures call for improvements in product performance and quality, and for reductions in development time scale [4].

The process of discovering the technological principles of a device, object, or a system through analysis of its structure, function and operation is known as Reverse Engineering (RE). Reverse engineering has become a viable method to create a 3D virtual model of an existing physical part for use in 3D CAD, CAM, CAE or other software [9]. The measured data alone, usually represented as a point cloud, lacks topological information and is therefore often processed and modeled into a more usable format such as a triangular-faced mesh, a set of NURBS surfaces, or a CAD model. A digital 3D model must be constructed using a device that can analyze a real-world object or environment to collect data on its shape and possibly its appearance for example the color. This device is known as 3D scanner. Nowadays, many different technologies can be used to build 3D-scanning devices, but each of the technology comes with its own limitations, advantages and costs. Some of the limitations of this technology that still present are optical technologies encounter many difficulties with shiny, mirroring or transparent objects [3].

The quality of the surface plays a very important role in the performance of milling as a good-quality milled surface significantly improves fatigue strength, corrosion resistance, or creep life. Surface roughness also affects several functional attributes of parts, such as contact causing surface friction, wearing, light reflection, heat transmission, ability of distributing and holding a lubricant, coating, or resisting fatigue. An increase in cutting forces would degrade or reduce the surface finish [7]. Therefore, the desired finish surface is usually specified and the appropriate processes are selected to reach the required quality. The machining quality was assessed through the comparison of surface roughness, surface texture and dimensional control parameters.

\section{Methodology}

Scanning process was the first step done in this research. A gaming mouse is chosen as the physical part to be scanned and machined because of its sculptured shape. The scanning process was done by using 3D scanner model $700 \mathrm{CX}$. In 3D scanning, it was very hard to obtain fine surfaces from the raw data. Typical problems normally happened in the raw scanned data such as opened, overlapped and unfinished surfaces. Hence, it is really important to perform editing process in order to resolve all the problems mentioned. The editing process or smoothing process normally involves with sewing unattached surfaces, re-closing opened surfaces and re-creating overlapping surfaces. Geomagic studio was the software used to perform the editing process. After editing process completed, the file must be saved in igs / IGES or stp / STEP file format so that it could be read in Catia V5 and Delcam software for CAM preparation.

For the physical machining, 3-Axis CNC milling machine model DMC 635 Ecoline DMG Mori machine was the machine selected. The size of raw materials or stocks prepared were $150 \mathrm{~mm}$ x $100 \mathrm{~mm}$ x $50 \mathrm{~mm}$. The material was Aluminum 1000 series. Cutting tool of End Mill D16 High Speed Steel (HSS) four flutes is used to perform the roughing process. Meanwhile, Ball Nose Mill R6 (HSS) cutting tools were chosen to perform the machining on the surfaces which were to be analyzed in surface roughness analysis. In Catia V5, Advanced Machining workbench is utilized to create the CAM program. Machining process offered by Catia V5 for surface machining called "Sweeping" process. On the other hand, in Delcam software it was automatically selected by the software once the specific 
geometries of the 3D CAD model are defined. There were setups or settings which need to be set for both software. It is realized that some different terms used carry the same meanings such as "depth of cut" used in Catia V5 whereas " $Z$ increment" in Delcam. Table 1 indicates the settings have been applied for both software in preparing the CAM program whilst Fig. 1 shows the completed CAM programs for both software. Completed programs were then post processed using integrated post processor and finally transferred to the CNC machine for physical machining.

Surface Roughness is a measurable surface characteristic quantifying high frequency deviation from an ideal surface. It is usually described by the arithmetic mean value ( $\mathrm{Ra})$, based on the mean of the normal deviations from a nominal surface over a specified "cut off" length and normally measured in micrometers $(\mu \mathrm{m})$. This process was done using Mitutoyo surface roughness tester in metrology laboratory. Moreover, this analysis used a contact surface roughness tester to measure the surface finish. In other words, this method involves dragging a measurement stylus in traverse direction on the surface of the sample. The surface features were measured relatively to the drive unit reference surface. Hence, this accurately measures waviness and finally stepped features in addition to the surface roughness.

Table 1. Settings / parameters applied for both software in preparing the CAM program

\begin{tabular}{|l|c|l|l|l|}
\hline \multicolumn{2}{|c|}{ Catia V5 Software } & \multirow{2}{c|}{ Delcam Software } \\
\hline Spindle speed & $7000 \mathrm{Rpm}$ & & Spindle speed & $7000 \mathrm{Rpm}$ \\
\hline Offset on part & $0.5 \mathrm{~mm}$ & & Finishing allowance & $0.5 \mathrm{~mm}$ \\
\cline { 1 - 1 } $\begin{array}{l}\text { Machining } \\
\text { tolerance }\end{array}$ & $0.1 \mathrm{~mm}$ & & $\begin{array}{l}\text { Machining } \\
\text { tolerance } \\
\text { \& Stepover }\end{array}$ & $0.1 \mathrm{~mm}$ \\
\hline & & \multicolumn{3}{|c|}{ ROUGHING } \\
\hline
\end{tabular}

\begin{tabular}{|c|c|c|c|}
\hline \multicolumn{2}{|c|}{ Catia V5 Software } & \multicolumn{2}{|c|}{ Delcam Software } \\
\hline Spindle speed & $8000 \mathrm{Rpm}$ & Spindle speed & $8000 \mathrm{Rpm}$ \\
\hline $\begin{array}{l}\text { Machining } \\
\text { tolerance }\end{array}$ & $0.1 \mathrm{~mm}$ & Machining tolerance & $0.1 \mathrm{~mm}$ \\
\hline $\begin{array}{l}\text { Maximum distance } \\
\text { between pass }\end{array}$ & $0.05 \mathrm{~mm}$ & Stepover & $0.05 \mathrm{~mm}$ \\
\hline Offset on part & $0 \mathrm{~mm}$ & Finishing allowance & Omm \\
\hline Cut of depth & $0.01 \mathrm{~mm}$ & $\mathrm{Z}$ increment & $0.01 \mathrm{~mm}$ \\
\hline \multicolumn{2}{|c|}{ SIVEEPING } & \multicolumn{2}{|c|}{ FINISHING } \\
\hline
\end{tabular}




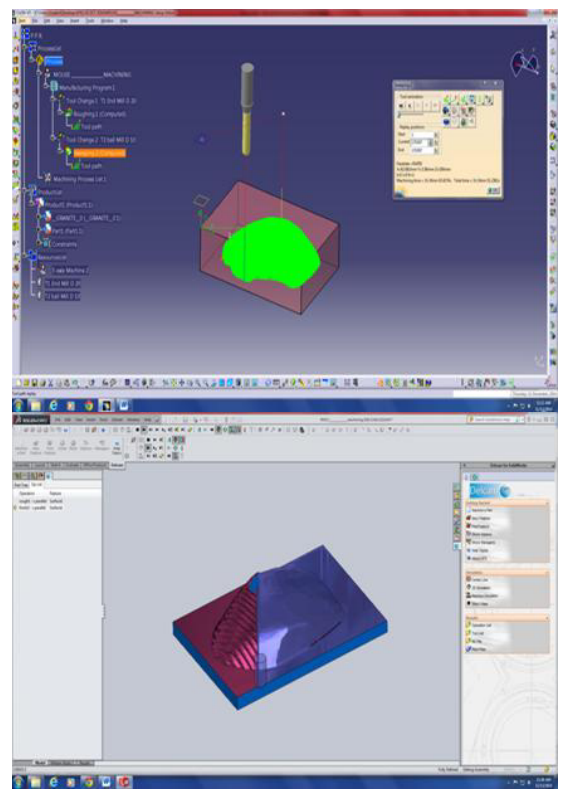

Fig. 1. Completed CAM program in Catia V5 (top) and Delcam (bottom)

\section{Result and discussion}

In measuring the surface finish, there were ten points randomly picked on the top surface of the machined parts. Various locations have been chosen to be analyzed. Eight points were taken on the main part. Meanwhile, two points were on the bottom of the machined part. All points taken for both machined parts were approximately on the same locations. Furthermore, three readings are taken for each identified point and the average value is calculated. The stylus traverse distance was set constantly at $5 \mathrm{~mm}$ at every single reading. Fig. 2 indicates the location of the points taken for the surface analysis.

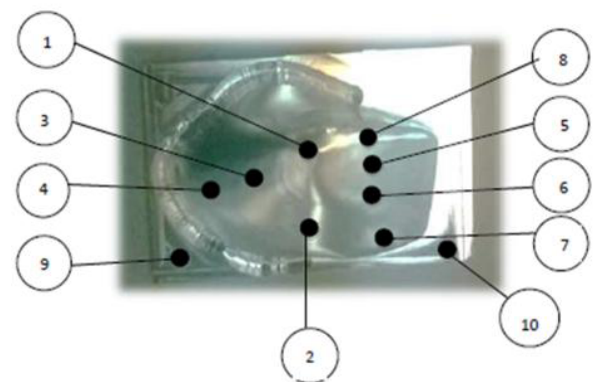

Fig. 2. Points taken for surface roughness analysis for both machined parts 
CATIA V5 SOFTWARE

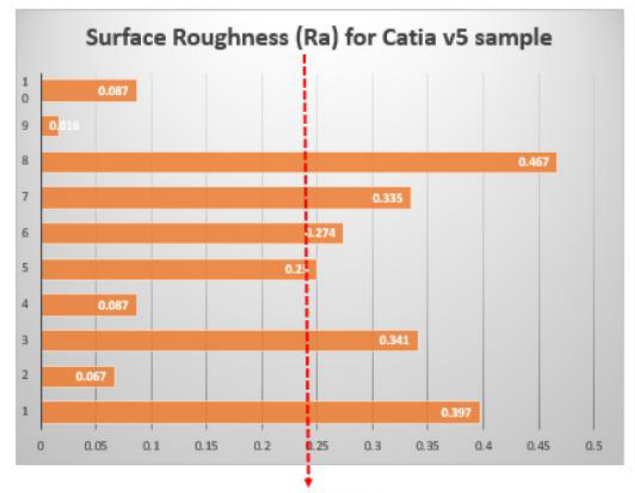

Average $=0.232$
DELCAM SOFTWARE

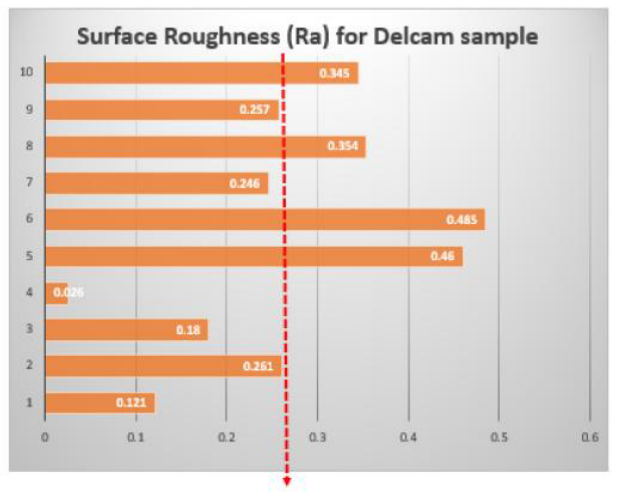

Average $=0.274$

Fig. 3. Comparison of surface roughness average values for the 10 points taken

From the result illustrates above, it is obviously shown that the highest average value for Catia V5 is $0.467 \mu \mathrm{m}$ at the $8^{\text {th }}$ point whilst for Delcam's is $0.485 \mu \mathrm{m}$ representing the $6^{\text {th }}$ point. On the other hand, the best surface roughness value falls at the point marked as 9 for Catia V5 with the value of $0.016 \mu \mathrm{m}$. Meanwhile, for Delcam it falls at the $4^{\text {th }}$ point with $0.026 \mu \mathrm{m}$. The location of the $9^{\text {th }}$ point was located on the bottom side. However, the location for the $4^{\text {th }}$ point for the Delcam was located on the main part itself. Nevertheless, it appears the average value obtained for Catia V5 is $0.232 \mu \mathrm{m}$ shows slightly better result to be compared to the Delcam's which is $0.274 \mu \mathrm{m}$. This finding highlights that the same scanned 3D CAD model programmed by Catia V5 resulted slightly better surface finish in average than programmed by Delcam.

The main factor contributes to the result obtained was possibly caused by the different way of preparing the program. Although the same 3D CAD model were used and the same parameters applied, somehow the differences in determining the important settings whilst preparing the CAM program such as tool path direction and machining processes. In Catia V5 users were given options in determining the direction of tool path as this was not being offered in Delcam. In this study, the direction of the tool path selected was along the length of the part to be machined. However, in Delcam the tool path was automatically calculate which was opposite direction from the one selected in Catia V5 and at certain areas the tool paths looked undefined movement. Furthermore, in Delcam there were too many shortcuts to simplify the machining program compared to Catia V5. Machining parameters were also automatically calculated from the library referring to the range set by the users as not in the practice of Catia V5. Catia V5 emphasizes details in each step and process compared to Delcam. There were two machining processes chosen in Catia V5 namely roughing and sweeping process. Sweeping process was chosen because of its ability in generating tool paths for curved or sculptured surfaces in point milling. On the other hand, in Delcam machining process were defined automatically by the software once all necessary geometries were chosen. The differences mentioned are presented in Fig. 4.

Ultimately, Catia V5 offers higher flexibility in determining the way of CAM program to be created than Delcam. Nevertheless, simplification and automatic defined by the software makes programming time in Delcam much faster than Catia V5. Importantly, both software are able to produce the desired machined part. 


\section{Conclusion}

In this study, the effect of surface finish of machined parts which were programmed by Catia V5 and Delcam applying one of Reverse Engineering methods namely 3D Scanned Data have been investigated. The result reveals that the surface finish of machined part programmed by Catia V5 slightly better than Delcam in average although the same 3D CAD data is used. Important conclusion drawn from this work is that; differences in preparing the CAM program especially on the tool path direction as well as the details of machining processes involve will also somehow effect the surface finish of the machined part even though the same 3D CAD model is used as the reference. In particular, further research should be conducted on study of dimensional accuracy in producing machined part from scanned data to be compared to the actual part for both meant software.

Author acknowledges, with gratitude, authors' debt of thanks to Universiti Teknikal Malaysia Melaka (UTeM) and to the funding body; Ministry of Higher Education Malaysia for the research grant (RAGS/1/2014/TK01/UTEM/B00079).

\section{References}

1. Abbott, Steven, SPE (Surface Profile Explorer), Abbott Apps, (Steven Abbott TCNF Ltd. 2014)

2. R. Baptista and J.F. Antune Simoes, J. Mater. Process. Technol., 103, 398 (1999)

3. F. Bernardini, H.E. Rushmeier, The 3D Model Acquisition Pipeline, (Compute Graphics Forum 2002)

4. Chris McMahon, Jimmie Brownie, CAD/CAM Principle Practice and Manufacturing Management, $2^{\text {nd }}$ Edition, (Prentice-Hall, 1999)

5. R. Alavala Chennakesava, CAD/CAM Concept and Application, (Prentice-Hall India. 2008)

6. R. Dubovska, J. Jambor, J. Majerik, Procedia Eng., 69, 638 (2014)

7. S.A. Sundi, M.R. Muhamad, B.A Bakar, R.I.R. Abdullah, Sci. Int. (Lahore), 26, 1869 (2014)

8. Y.W. Sun, D.M. Guo, Z.Y. Jia, J. Mater. Process. Technol., 180, 74 (2006)

9. T. Várady, R.R. Martin, J. Cox, Comput. Aided Des., 253 (1997) 